\title{
Amyloidosis in transgenic mice expressing murine amyloidogenic apolipoprotein A-II (Apoa2 $\left.{ }^{C}\right)$
}

\author{
Fengxia Ge ${ }^{1}$, Junjie Yao ${ }^{1,2}$, Xiaoying Fu ${ }^{1}$ Zhanjun Guo ${ }^{1}$, Jingmin Yan ${ }^{1}$, Beiru Zhang ${ }^{1}$, Huanyu Zhang ${ }^{1}$,
} Hiroshi Tomozawa ${ }^{3}$, Junichi Miyazaki ${ }^{4}$, Jinko Sawashita ${ }^{1}$, Masayuki Mori ${ }^{1}$ and Keiichi Higuchi ${ }^{1,2}$

In mice, apolipoprotein A-II (apoA-II) self-associates to form amyloid fibrils (AApoAll) in an age-associated manner. We postulated that the two most important factors in apoA-II amyloidosis are the Apoa2 ${ }^{C}$ allele, which codes for the amyloidogenic protein APOA2C (Gln5, Ala38) and transmission of amyloid fibrils. To characterize further the contribution of the Apoa $2^{C}$ allele to amyloidogenesis and improve detection of amyloidogenic materials, we established transgenic mice that overexpress APOA2C protein under the cytomegalovirus (CMV) immediate early gene (CMV-IE) enhancer/ chicken $\beta$ promoter. Compared to transgene negative $\left(\mathrm{Tg}^{-/-}\right)$mice that express apoA-Il protein mainly in the liver, mice homozygous $\left(\mathrm{Tg}^{+/+}\right)$and heterozygous $\left(\mathrm{Tg}^{+/-}\right)$for the transgene express a high level of apoA-II protein in many tissues. They also have higher plasma concentrations of apoA-II, higher ratios of ApoA-II/apolipoprotein A-I (ApoA-I) and higher concentrations of high-density lipoprotein (HDL) cholesterol. Following injection of AApoAll fibrils into $\mathrm{Tg}^{+/+}$mice, amyloid deposition was observed in the testis, liver, kidney, heart, lungs, spleen, tongue, stomach and intestine but not in the brain. $\mathrm{In} \mathrm{\textrm {Tg } ^ { + / + }}$ mice, but not in $\mathrm{Tg}^{-/-}$mice, amyloid deposition was induced by injection of less than $10^{-8} \mu \mathrm{g}$ AApoAll fibrils. Furthermore, deposition in $\mathrm{Tg}^{+/+}$mice occurred more rapidly and to a greater extent than in $\mathrm{Tg}^{-/-}$mice. These studies indicate that increased levels of APOA2C protein lead to earlier and greater amyloid deposition and enhanced sensitivity to the transmission of amyloid fibrils in transgenic mice. This transgenic mouse model should prove valuable for studies of amyloidosis.

Laboratory Investigation (2007) 87, 633-643; doi:10.1038/labinvest.3700559; published online 30 April 2007

KEYWORDS: amyloidosis; Apoa2 $^{c}$ gene; overexpression; transgenic mouse; transmission

Amyloidosis is a group of diseases caused by structural disorders of proteins whereby normally soluble proteins are deposited in tissues as highly ordered, insoluble amyloid fibrils made up of $\beta$-pleated sheets. ${ }^{1}$ Several serious human diseases are associated with amyloid fibril deposition such as Alzheimer's disease, type II diabetes, prion disease and familial amyloid polyneuropathy. ${ }^{2,3}$ Several apolipoprotein family proteins have been identified as major components of amyloid fibrils. Apolipoprotein serum amyloid A (ApoSAA), apolipoprotein A-I (apoA-I), apolipoprotein A-II (apoA-II) and apolipoprotein A-IV (apoA-IV) are currently considered to be amyloidogenic apolipoproteins. In mice, apoA-II, the second most abundant apolipoprotein in serum high-density lipoprotein (HDL), associates to form amyloid fibrils (AApoAII) and is deposited in the body, though not in brain, in an age-associated manner. ${ }^{4,5}$ In laboratory mice, three major alleles $\left(\right.$ Apoa $^{a}, A$ Apoa $2^{b}$ and $A$ poa $\left.2^{c}\right)$ of the apoA-II gene encode three variants of the apoA-II protein: APOA2A with Pro5 and Met26, APOA2B with Pro5 and Val38 and APOA2C with Gln5 and Ala38, respectively. ${ }^{6,7}$ Several genetic analyses have indicated that the Apoa ${ }^{c}$ allele might markedly accelerate age-associated deposition of AApoAII. ${ }^{8-10}$

Previously, we have described prion-like transmission of AApoAII amyloidosis in which intravenous, peripheral and oral injection of AApoAII amyloid fibrils markedly accelerated amyloid deposition in young R1.P1-Apoa2 $2^{c}$ mice. ${ }^{11,12}$ We also observed that young R1.P1-Apoa2 ${ }^{c}$ mice showed rapid onset of amyloidosis when they share cages with old R1.P1-Apoa2 ${ }^{c}$ mice with severe amyloid deposits. Furthermore, offspring nursed by amyloidosis-induced mothers showed early development of amyloidosis. ${ }^{12,13}$ The propagation of amyloidosis among mice probably occurred

\footnotetext{
'Department of Aging Biology, Institute on Aging and Adaptation, Shinshu University Graduate School of Medicine, Matsumoto, Japan; ${ }^{2}$ The Core Research for Evolutional Science and Technology (CREST), Japan Science and Technology Corporation, Tokyo, Japan; ${ }^{3}$ Research Center for Human and Environmental Science, Shinshu University, Matsumoto, Japan and ${ }^{4}$ Division of Stem Cell Regulation Research, Osaka University Medical School, Osaka, Japan 
through the consumption of AApoAII fibrils contained in feces and milk. Injection of AApoAII fibrils also induced amyloidosis in less-amyloidogenic mouse strains with Apoa $2^{a}$ or $A$ poa $2^{b}$ alleles. ${ }^{13,14}$ Injection of various kinds of amyloid fibrils into R1.P1-Apoa $2^{c}$ mice also induced amyloidosis. ${ }^{15}$ These results demonstrated that a common amyloid fibril structure could serve as a seed for amyloid fibril formation (cross-seeding) in vivo. Prion-like transmission was also reported in mouse inflammation-associated amyloid A (AA) amyloidosis. ${ }^{16,17}$ Many factors such as aging, primary sequence and mutation of amyloid proteins, genetic background of patients, as well as epigenetic factors, including inflammation, food composition and rearing conditions, may influence fibril formation and deposition in tissues. Transmission of amyloid fibrils from the environment may influence fibril formation as an important epigenetic factor. ${ }^{18}$

The R1.P1-Apoa $2^{c}$ strain has been a valuable model system for the investigation of genetic and epigenetic factors in amyloid deposition. However, at least 2-3 months are required to evaluate the degree of amyloid deposition even after the injection of AApoAII fibrils. In addition, it has been shown that the efficiency with which amyloid fibrils induce amyloidosis is significantly decreased by cross-seeding compared to self-seeding by homologous amyloid fibrils. ${ }^{19-21}$ In fact, the rate of fibril formation is dependent on the concentration of amyloid protein both in vitro and in vivo. To develop an advanced model for investigating the mechanism of amyloidosis, we established a transgenic mouse strain that overexpresses amyloidogenic Apoa2 ${ }^{c}$ mRNA.

In this study of $m A p o a 2^{c}$ transgenic mice, we found that treatment with a very small quantity of amyloid fibrils led to greater amyloid deposition and higher levels of plasma apoAII compared to non-transgenic mice.

\section{MATERIALS AND METHODS}

\section{Establishment of Apoa2 ${ }^{c}$ Transgenic Mouse}

cDNA of the mouse Apoa2 $2^{c}$ gene was isolated by reverse transcription-PCR (RT-PCR) of messenger RNA extracted from R1.P1-Apoa $2^{c}$ mouse liver. The pmApoa ${ }^{c}$-CAGGS vector DNA containing mouse Apoa ${ }^{c}$ cDNA inserted between cytomegalovirus (CMV) immediate early gene (CMVIE) enhancer/chicken $\beta$-actin promoter and rabbit $\beta$-globin polyA signal ${ }^{22}$ was microinjected into fertilized eggs of BDF2 mice. Then, the eggs were transplanted into the uteri of pseudo-pregnant ICR mice. Transgenic founders were identified by PCR using primers for Apoa2-1 (5'-AGGAATTC CATCATGAAGCTGCTCGC- $3^{\prime}$ ) and $\mathrm{r} \beta$ Glb-R (5'-TAGCCA GAAGTCAGATGCTC- $3^{\prime}$ ). These primers can distinguish positive and negative mice by amplifying a $495 \mathrm{bp}$ fragment of the transgene (Figure 1a). Since BDF2 mice have a less amyloidogenic Apoa $2^{a}$ allele, the founder mice were crossed with R1.P1-Apoa $2^{c}$, a congenic strain of mice with Apoa ${ }^{c}$ from the senescence-accelerated mouse prone strain (SAMP1) on the genetic background of the senescenceaccelerated mouse-resistant strain (SAMR1), to make trans- genic mice homozygous for the Apoa2 $2^{c}$ allele $\left(\right.$ Apoa2 $2^{c} \mathrm{Tg}^{+1+}$, $A$ poa $\left.2^{c / c}\right)$. To minimize the possible effects of the genetic background, transgenic mice were backcrossed with R1.P1Apoa $2^{c}$ mice for six generations. The Apoa $2^{c}$ allele was identified using allele $c$-specific primers of A2/acc-F (5'-AAGAGACAGGCGGACGGACA- ${ }^{\prime}$ ) and A2/acc-R (5'GAGGTCTTGGCCTTCTCCAC-3'). Seven transgene-positive founders were obtained, but only one founder (I-6) could pass the transgene to the next generation. Thus, all studies were in a line derived from founder I- 6 .

Mice were maintained under specific pathogen free (SPF) conditions at $24 \pm 2^{\circ} \mathrm{C}$ with a light-controlled regimen $(12 \mathrm{~h}$ light/dark cycle) in the Division of Laboratory Animal Research, Department of Life Science, Research Center for Human and Environment Science, Shinshu University. A commercial diet containing 5.3\% fat (MF; Oriental Yeast, Tokyo, Japan) and tap water were available ad libitum. All experiments were performed with the consent of the Animal Care and Use Committee of Shinshu University School of Medicine.

\section{Chromosome Localization of the Integrated Apoa2 $^{c}$ cDNA Vector}

The location of the inserted Apoa $2^{c}$ cDNA vector in the chromosome was determined by chromosome walking according to the protocol of the DNA Walking SpeedUp Kit (Seegene Inc., Seoul, Korea). We used two PCRs to amplify genomic DNA upstream of the inserted transgene in the transgenic mice. In the first PCR, we used the primers of DW-ACP2 (5'-ACP-TGGTC- $\left.3^{\prime}\right)$ and R203 (5'-CCATTGACGTCAATGGAAAGTCC- $\left.3^{\prime}\right)$. Cycling conditions were as follows: one cycle at $94^{\circ} \mathrm{C}$ for $30 \mathrm{~s} ; 30$ cycles at $94^{\circ} \mathrm{C}$ for $40 \mathrm{~s}$, $55^{\circ} \mathrm{C}$ for $40 \mathrm{~s}, 72^{\circ} \mathrm{C}$ for $2 \mathrm{~min}$; and one cycle at $72^{\circ} \mathrm{C}$ for $7 \mathrm{~min}$. The second PCR was performed on $2 \mu \mathrm{l}$ of PCR product from the first round of PCR with the second set of primers, DW-ACP-N (5'-ACPN-GGTC- $\left.3^{\prime}\right)$ and R180 (5'-CTATTGGCGTTACTATGGGAACATACG- $3^{\prime}$ ) (Figure 1a). Cycling conditions for the second round of PCR were as follows: one cycle at $94^{\circ} \mathrm{C}$ for $30 \mathrm{~s} ; 30$ cycles at $94^{\circ} \mathrm{C}$ for $40 \mathrm{~s}$, $60^{\circ} \mathrm{C}$ for $40 \mathrm{~s}, 72^{\circ} \mathrm{C}$ for $2 \mathrm{~min}$; and one cycle at $72^{\circ} \mathrm{C}$ for 7 min. PCR products were resolved on $2 \%$ agarose gels. Next, we used the same method to amplify sequences downstream of the inserted cDNA using primers F2381 (5'-GCCTAAT GAGTGAGCTAACTCAC-3') and 13-L1-F (5'-CACCTGAA AAAATGTTCAACATCCTTAG- ${ }^{\prime}$ ). We determined their location in the chromosome by comparing their sequences with the draft sequence of the mouse genome.

We also performed PCRs using the primers of $13 \mathrm{~F}$ (5'-GCAAGCAGTGTCCAGTTAGG-3') and R112 (5'-CCA GGCGGGCCATTTACCGTAAGT- $3^{\prime}$ ) and with the primers of $13 \mathrm{~F}$ and 13R (5'-CAGGCTCATACTACTTGCAG- $3^{\prime}$ ) to distinguish homozygous, heterozygous and negative mice (Figure 1b). 
a

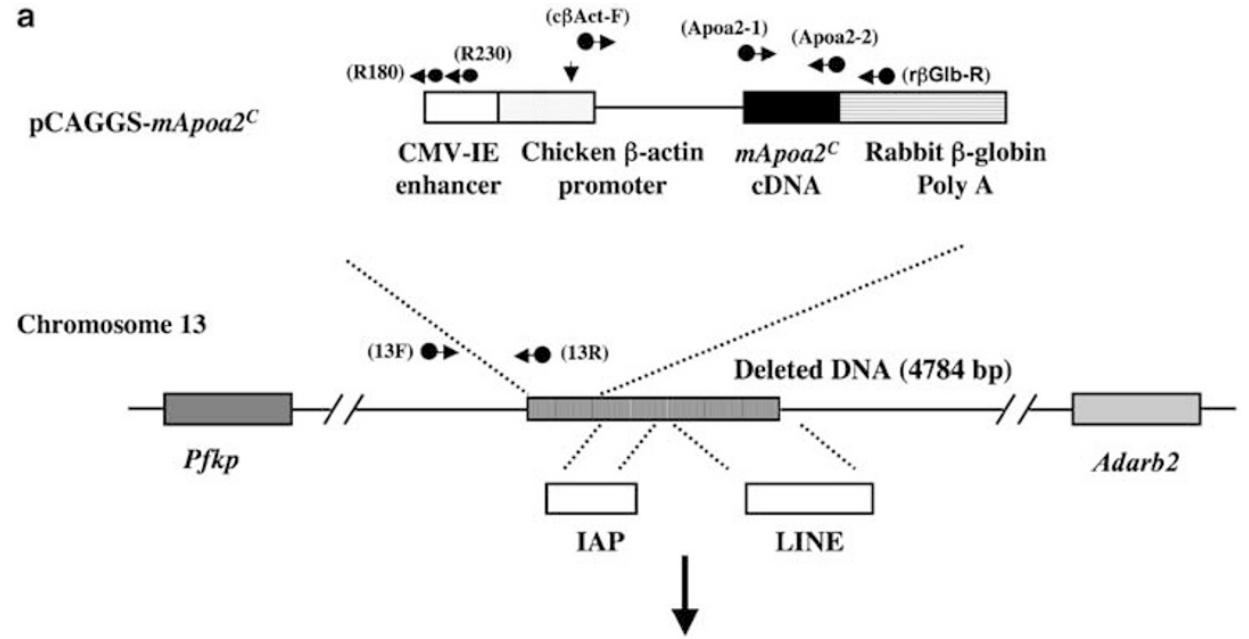

Transgenic Mouse

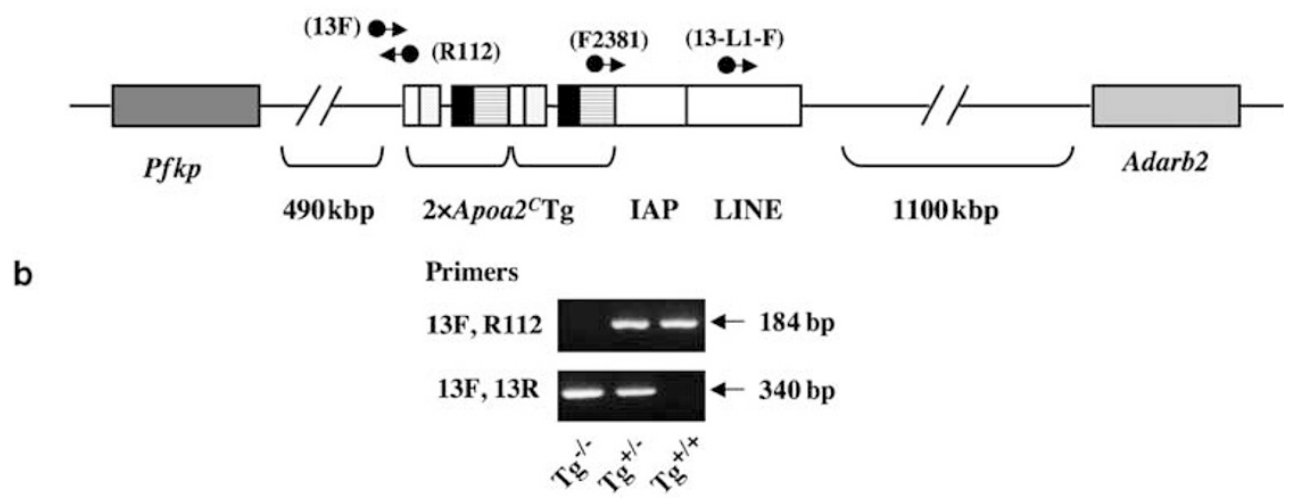

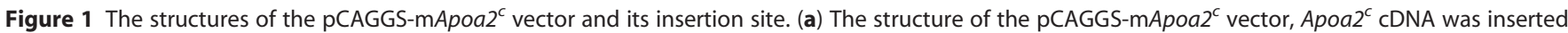
between CMV-IE enhancer/chicken $\beta$-actin promoter and rabbit $\beta$-globin Poly A site. pCAGGS-mApoa2 $2^{c}$ vector was microinjected into fertilized eggs. It was inserted in chromosome 13 associated with the deletion of genomic DNA (4789 bp) and insertion of IAP and LINE elements. Adjoining genes (Pfkp and Adarb2) are 490 and $1100 \mathrm{kbp}$ away from the integrated site. Two copies of pCAGGS-mApoa2 ${ }^{c}$ were integrated in tandem in the transgenic mice. Arrow, the transcription start codon; R180, R230, F2381 and 13-L1-F primers used for chromosomal localization of the transgene; Apoa2-1, r $\beta$ Glb-R, 13F and R112 primers used for identification of the transgenic mice; $c \beta$ Act- $F$ and Apoa2-2 primers used for detection of the apoA-II mRNA transcribed from transgene. (b) Identification of the negative $\left(\mathrm{Tg}^{-/}\right)$, heterozygous $\left(\mathrm{Tg}^{+/-}\right)$and homozygous $\left(\mathrm{Tg}^{+/+}\right)$mice for the transgene by PCR. Specific primer pairs (13F and R112, Figure 1a) recognizing inserted transgene and pairs (13F and 13R, Figure 1a) recognizing wild-type genomic sequence were used to distinguish $\mathrm{Tg}^{-1-}$, $\mathrm{Tg}^{+/-}$and $\mathrm{Tg}^{+1+}$ mice.

\section{Analysis of the Expression of apoA-II in the Transgenic Mice}

Total RNA was extracted from mouse organs using QIAamp RNA Mini Kits (Qiagen Inc., Valencia, CA, USA) according to manufacturer's protocol. First strand cDNA was synthesized using ReverTra Ace-á kit (Toyobo, Ltd, Osaka, Japan) and used in PCR. We used primers Apoa2-1 (5'-AGGAA TTCCATCATGAAGCTGCTCGC-3') and Apoa2-2 ( $5^{\prime}$-AGG AATTCCTCACTTAGCCGCAGGAGC- $3^{\prime}$ ) for RT-PCR of the apoA-II mRNA transcribed from endogenous apoA-II gene and transgene. We used primers $c \beta$ Act-F $\left(5^{\prime}\right.$-ACTGACCGCGTTACTCCCAC-3') and Apoa2-2 for the apoA-II mRNA transcribed from transgene (Figure 1a). We carried out RT-PCR for the housekeeping gene $\beta$-actin using primers $\mathrm{m} \beta$ Act-F ( $5^{\prime}$-ACAATGAGCTGCGTGTGGCC- $\left.3^{\prime}\right)$ and m $\beta$ Act-R ( $5^{\prime}$-CCTCGTAGATGGGCACAGTG-3').
Following perfusion with PBS, organs were removed from mice and maintained at $-80^{\circ} \mathrm{C}$ until proteins could be extracted for western blot analysis of apoA-II protein. ${ }^{23}$ Samples were loaded on Tris-Tricine/SDS-16.5\% polyacrylamide gels electrophoresis (PAGE) as follows: $50 \mu \mathrm{g}$ of protein extracted from the testis, liver, kidney, heart, lungs, spleen, tongue and stomach, $100 \mu \mathrm{g}$ from brain and intestine and $0.1 \mu \mathrm{l}$ of the plasma. ${ }^{24}$ After electrophoresis at $15 \mathrm{~mA}$ for $6 \mathrm{~h}$, proteins were transferred to a polyvinylidene difluoride membrane using a semidry western blot apparatus (Nihon Eido, Tokyo, Japan) at $150 \mathrm{~mA}$ for $1.5 \mathrm{~h}$. The membrane was then reacted with primary antibody solution, either with polyclonal rabbit anti-mouse apoA-I (diluted 1:2000) or apoA-II antisera (diluted 1:4000) in 5\% skim milk in PBS containing $0.1 \%$ Tween 20 (T-PBS) for $1 \mathrm{~h}$ at room temperature with gentle shaking. ${ }^{25}$ Membranes were incubated 
for $1 \mathrm{~h}$ with horseradish peroxidase (HRP)-conjugated antirabbit IgG (Daiichi Pure Chemicals, Tokyo, Japan) solution (1:500). ApoA-I and apoA-II were detected by the enhanced chemiluminescence (ECL) method (Amersham International, Buckinghamshire, UK) and quantitated using a densitometric image analyzer with NIH Images Ver. 1.61.

\section{Plasma Lipids, Lipoprotein Quantity and HDL Particle Size}

Plasma was collected from mice that had fasted overnight. Plasma total cholesterol levels were determined by an enzymatic procedure (cholesterol C test, Wako Pure Chemical Industries, Osaka, Japan). HDL cholesterol was estimated according to a modified heparin-manganese precipitation procedure (HDL-cholesterol Test, Wako). To determine the HDL particle size, plasma $(3 \mu \mathrm{l})$ pre-stained for lipids by Sudan Black B was electrophoresed on a nondenaturing PAGE gel containing a 5-15\% linear polyacrylamide gradient. ${ }^{26}$ Electrophoresis was carried out at $25 \mathrm{~mA}$ for $2 \mathrm{~h}$. The distribution of apoA-II protein among the HDL species was determined by western blot analysis of $0.1 \mu$ l plasma separated by native PAGE. Cholesterol profile in plasma lipoproteins was analyzed by a dual detection high performance liquid chromatography (HPLC) system with two tandem TSKgel LipopropakXL columns ( $300 \AA ̊ 7.8 \mathrm{~mm})$ according to the method of Usui $e a^{27}$ (Liposearch System, Skylight Biotech Inc, Akita, Japan).

\section{Isolation of AApoAll Fibrils and Induction of AApoAll Amyloidosis}

AApoAII amyloid fibrils were isolated from the liver of an 18month-old R1.P1-Apoa $2^{c}$ mouse with severe amyloidosis as described by Pras et al. ${ }^{28}$ The isolated amyloid fibril fraction was further purified by ultracentrifugation as described previously. ${ }^{11}$ Pellets after ultracentrifugation were resuspended in distilled water and kept at $-70^{\circ} \mathrm{C}$. For induction of AApoAII amyloidosis, a single dose of $10^{-8}, 10^{-5}, 10^{-3}, 10^{-1}$ and $1 \mu \mathrm{g}$ of sonicated AApoAII amyloid fibrils ${ }^{13}$ were injected into the tail vein of 2-month-old transgene positive and negative mice. After 1, 2 and 3 months, the treated mice were killed by cardiac puncture under diethyl ether anesthesia, and amyloid deposition was determined.

\section{Detection of Amyloid Deposition}

Deposition of amyloid fibrils was identified by polarizing microscopy using Congo Red-stained sections in which green birefringence indicates the presence of amyloid. ${ }^{29}$ Amyloid fibril protein, AApoAII and AA proteins were identified immunohistochemically using the avidin-biotin HRP complex method with specific antiserum against mouse AApoAII or AA. ${ }^{5}$ The intensity of the AApoAII amyloid deposition was determined semi-quantitatively using the amyloid index (AI) parameter. The AI parameter represents the average degree of AApoAII deposition, graded 0 to 4 , in the seven organs examined (liver, heart, spleen, tongue, stomach, intestine and skin) in Congo Red stained sections. ${ }^{13}$ Tissues were examined by two independent observers who were blinded to the experimental protocol.

\section{Transmission Electron Microscopy}

Aliquots of $5 \mu \mathrm{l}$ of amyloid fibril fraction isolated from liver of homozygous mouse treated by AApoAII were diluted with $45 \mu \mathrm{l}$ distilled water, and $20 \mu \mathrm{l}$ aliquots of the diluted fraction were applied to 400-mesh collodion-coated copper grids (Nissin EM Co. Ltd, Tokyo, Japan) for $1 \mathrm{~min}$ and subjected to negative staining with $20 \mu \mathrm{l}$ of $1 \%$ phosphotungstic acid ( $\mathrm{pH}$ 7.0) for $1 \mathrm{~min}$. The negative stained samples were observed with an electron microscope (1200 EX; JEOL, Tokyo, Japan) operated at $80 \mathrm{kV}$.

\section{Statistical Analysis}

A Statview software package (Abacus Concepts, Berkeley, CA, USA) was used to analyze the data. All data are presented as the mean \pm s.d. Student's $t$ test was used for all data except for AI. The Mann-Whitney $U$-test was used to analyze the AI of AApoAII deposition.

\section{RESULTS}

Establishment of the mApoa2 $^{c}$ Transgenic Mouse Strain To study the mechanism of amyloidogenesis and to generate a novel model mouse strain with improved sensitivity to amyloidogenic materials in the environment, the amyloidogenic Apoa ${ }^{c}$ gene was introduced into the mice. A $320 \mathrm{bp}$ Apoa $2^{c}$ cDNA fragment was amplified and inserted into the vector between the CMV-IE enhancer/chicken $\beta$-actin promoter and the rabbit $\beta$-globin polyadenylation site. The construct was linearized with SalI and PstI, then microinjected into fertilized eggs. Transgenic offspring were screened by PCR, using primers specific for the transgene spanning Apoa $2^{c}$ gene and rabbit $\beta$-globin polyadenylation site (Figure 1a). One line of the founder mice was bred successfully for further studies.

We used the DNA walking PCR procedure with primers annealed to the $5^{\prime}$ and $3^{\prime}$ end of the pCAGGS-mApoa $2^{c}$ vector to localize the integrated chromosomal site. DNA sequencing of the genome surrounding the integrated vector revealed that it integrated near the centromere of chromosome 13 (Figure 1a). In association with integration of the vector, intracisternal A particles (IAP) and long interspersed nuclear elements (LINE) were integrated together in tandem and a 4784 bp genomic segment was deleted. Adjoining genes ( $P f k p$; phosphofructokinase platelet and Adarb2; adenosine deaminase, RNA-specific, B2) are 490 and $1100 \mathrm{kbp}$ away from the integrated site. The results indicated that homozygous $\mathrm{Tg}^{+1+}$ mice had four additional copies and heterozygous $\mathrm{Tg}^{+/-}$mice had two extra copies of the Apoa ${ }^{c}$ gene in addition to the two endogenous copies (Figure 1a). We designed primers that recognized deleted chromosomal DNA and integrated vector sequences to distinguish homozygous $\left(\mathrm{Tg}^{+/+}\right)$, heterozygous $\left(\mathrm{Tg}^{+/-}\right)$and wild-type $\left(\mathrm{Tg}^{-/-}\right)$mice 
for the transgene. PCR with these primers clearly identified the $\mathrm{Tg}^{-1-}, \mathrm{Tg}^{+/-}$and $\mathrm{Tg}^{+/+}$mice (Figure $1 \mathrm{~b}$ ). When we mated male and female heterozygous transgenic mice, the birth rates of $\mathrm{Tg}^{-/-}, \mathrm{Tg}^{+/-}$, and $\mathrm{Tg}^{+/+}$mice were $25.7,52.8$ and $21.5 \%$, respectively. All three strains with different transgenes developed normally and there were no marked pathological abnormalities.

\section{Expression of $A p o a 2^{c}$ in Tissues of $\mathrm{mApoa2^{c }}$ Transgenic Mice}

In $\mathrm{Tg}^{+1-}$ and $\mathrm{Tg}^{+1+}$ mice, high-level expression of $A p o a 2^{c}$ mRNA transcribed from the transgene (transgene Apoa2 ${ }^{c}$ mRNA) was found in the testis, liver, brain, kidney, heart, lungs, spleen, stomach and intestine by RT-PCR using transgene specific primers (Figure 2a). In contrast, transgene Apoa $2^{c}$ mRNA was not detected in any of the tissues from transgene negative $\left(\mathrm{Tg}^{-l-}\right)$ littermates. The total expression of $A$ poa $2^{c}$ mRNA was determined by RT-PCR with primers recognizing both endogenous and transgene Apoa2 $2^{c}$ mRNA. High-level expression of Apoa $2^{c}$ mRNA was detected in all tissues of $\mathrm{Tg}^{+/-}$and $\mathrm{Tg}^{+/+}$mice. However for $\mathrm{Tg}^{-1-}$ mice, expression was only detected in the liver, brain, lung and stomach (Figure 2b). The amount of apoA-II protein in tissues was analyzed by western blot analysis (Figure $2 \mathrm{~d}$ ). In $\mathrm{Tg}^{-/-}$mice, apoA-II protein was not detected in brain, stomach or intestine. In $\mathrm{Tg}^{+/+}$mice, apoA-II was elevated in all tissues except intestine. Furthermore, $\mathrm{Tg}^{+/+}$mice showed higher expression than $\mathrm{Tg}^{+/-}$mice.

\section{Plasma Apolipoproteins and Lipoproteins of $\mathrm{mApoa2}$ Transgenic Mice}

Plasma was collected from 2-month-old $\mathrm{Tg}^{-1-}, \mathrm{Tg}^{+/-}$and $\mathrm{Tg}^{+/+}$mice after fasting overnight. For reference, plasma was collected from C57BL/6J with Apoa2 ${ }^{a}$ and SAMR1 with Apoa $2^{b}$. The concentrations of apoA-I and apoA-II proteins were determined by western blot analysis (Figure 3a). The concentrations of apoA-II were lower in Apoa2 ${ }^{a}$ (C57BL/6J) and Apoa2 ${ }^{c}\left(\mathrm{Tg}^{-/-}\right)$mice. The Apoa2 $2^{c}$ transgene increased the concentration of apoA-II in $\mathrm{Tg}^{+/-}$and $\mathrm{Tg}^{+/+}$mice, while apoA-I concentrations were similar between strains. Quantitation of apoA-I and apoA-II levels revealed that the concentration of apoA-II in $\mathrm{Tg}^{+1+}$ mice, was 1.57- and 1.26fold greater than in $\mathrm{Tg}^{-1-}$ and $\mathrm{Tg}^{+/-}$mice, respectively. In contrast, significant changes were not observed in apoA-I concentration (Figure 3b). As a result, the ratio of apoA-II/ apoA-I was much higher in $\mathrm{Tg}^{+/+}$mice. Specifically, the ratio of apoA-II/apoA-I for $\mathrm{Tg}^{+/+}$mice was $1.65-$ and 1.36-fold higher than $\mathrm{Tg}^{-1-}$ and $\mathrm{Tg}^{+/-}$mice, respectively (Figure 3c). Plasma total cholesterol and HDL-cholesterol levels were also determined (Figure 3d). Total and HDLcholesterol levels were significantly higher in $\mathrm{Tg}^{+/-}$mice compared to $\mathrm{Tg}^{-1-}$ mice and further increased in $\mathrm{Tg}^{+/+}$ mice to the levels of SAMR1 mice. To determine the effect of additional Apoa $2^{c}$ expression on lipoprotein particles, we determined lipoprotein particle size by non-denatured PAGE and by gel permeation HPLC analysis. The predominant form observed on non-denaturing PAGE was $\mathrm{HDL}_{3}$. The sizes of $\mathrm{HDL}_{3}$ particles in $\mathrm{C} 57 \mathrm{BL} / 6 \mathrm{~J}$ and $\mathrm{Tg}^{-/-}$mice were smaller than those in SAMR1 mice (Figure 3e). Higher concentrations of apoA-II and higher ratios of apoA-II to apoA-I in $\mathrm{Tg}^{+/-}$ and $\mathrm{Tg}^{+1+}$ mice did not change the particle sizes of $\mathrm{HDL}_{3}$. The amount of apoA-II was increased in all $\mathrm{HDL}_{3}, \mathrm{HDL}_{2}$ and $\mathrm{HDL}_{1}$ particles in $\mathrm{Tg}^{+/-}$and $\mathrm{Tg}^{+/+}$mice. HPLC analysis confirmed that the quantity of HDL increased but the size of HDL did not change in $\mathrm{Tg}^{+/+}$mice, but the HDL particle size remained smaller than in SAMR1 mice (Figure 3f).

\section{AApoAll Amyloid Deposition in $\mathrm{mApoa2}^{\complement}$ Transgenic Mice}

To induce amyloidosis, sonicated AApoAII amyloid fibrils were injected intravenously into 2-month-old $\mathrm{Tg}^{-1-}, \mathrm{Tg}^{+/-}$ and $\mathrm{Tg}^{+/+}$mice at doses of $10^{-8}, 10^{-5}, 10^{-3}, 10^{-1}$, and $1 \mu \mathrm{g}$. Amyloid deposition in tissues was determined by Congo Red staining and immunohistochemistry after 2 months. In $\mathrm{Tg}^{+1+}$ mice, injection of $1 \mu \mathrm{g}$ AApoAII amyloid fibril

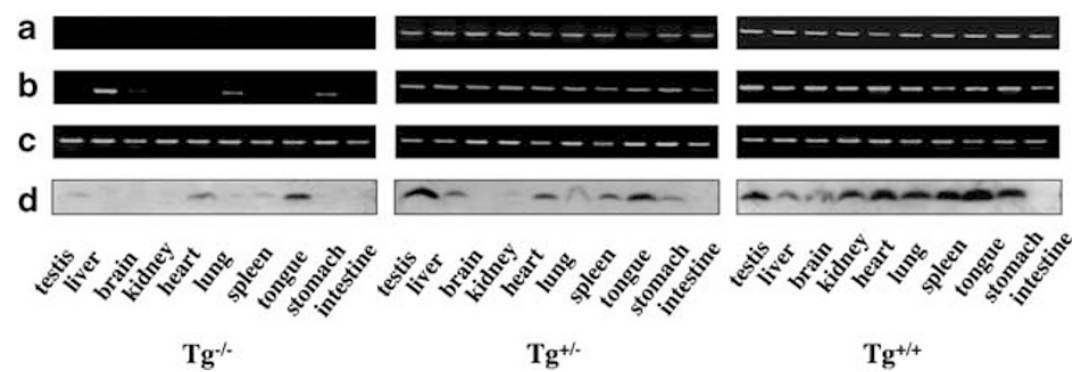

Figure 2 Expression of $A p o a 2^{c}$ in tissues. (a) The expression of transgene-mediated $A p o a 2^{c}$ mRNA was detected by RT-PCR using a specific primers pair (c $\beta$ Act-F and Apoa2-2; Figure 1a). The expression of Apoa2 ${ }^{c}$ mRNA from the transgenic gene was observed in all tissues examined; testis, liver, brain, kidney, heart, lungs, spleen, stomach and intestine in $\mathrm{Tg}^{+/-}$and $\mathrm{Tg}^{+/+}$mice but not in $\mathrm{Tg}^{-/-}$mice. (b) The expression of total Apoa $2^{C}$ mRNA originated both from endogenous and transgenic Apoa $2^{c}$ genes were detected by RT-PCR using the primer pair (Apoa2-1 and Apoa2-2; Figure 1a). Endogenous expression of Apoa $2^{c}$ mRNA was detected in the liver, brain, lungs and stomach in $\mathrm{Tg}^{-1-}$ mice. (c) The expression of housekeeping gene $\beta$-actin was examined as a control. (d) ApoA-II protein was analyzed by western blot analysis of the homogenate of each tissue. Endogenous apoA-II protein was detected only in the testis, liver, heart, lungs, spleen and tongue in $\mathrm{Tg}^{-/-}$mice. However, apoA-Il was detected in all tissues except intestine in $\mathrm{Tg}^{+/+}$mice. 
a
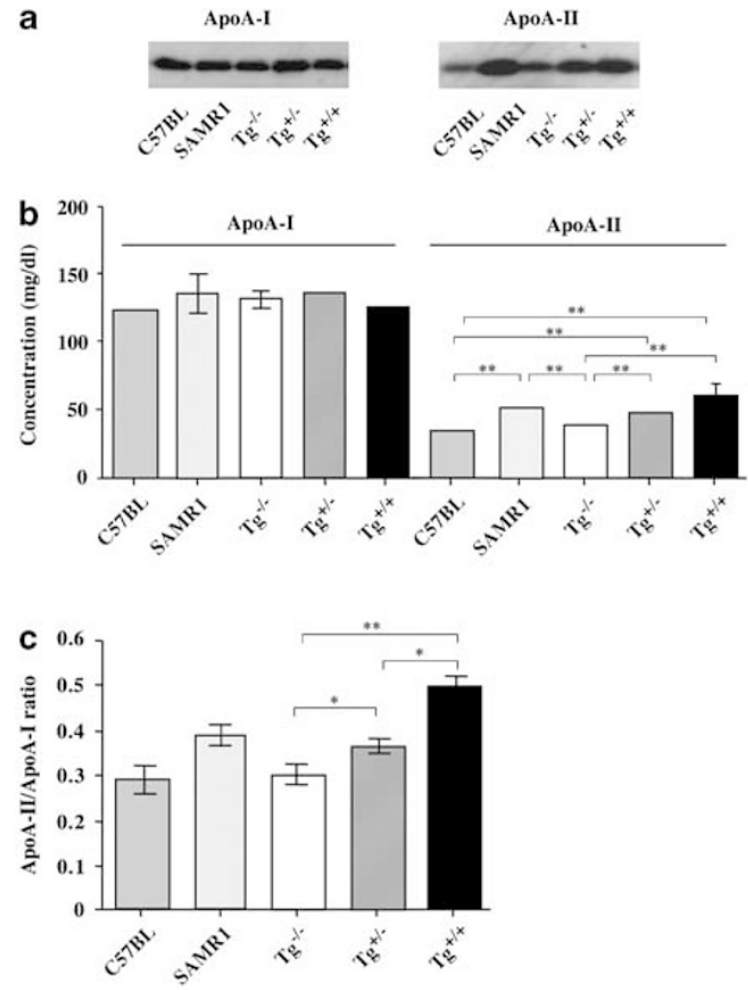

d

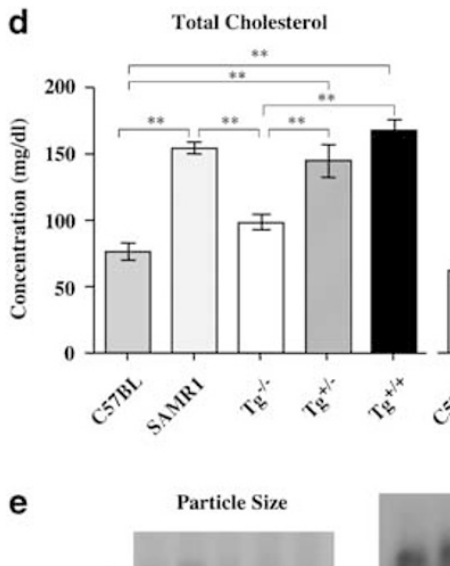

e
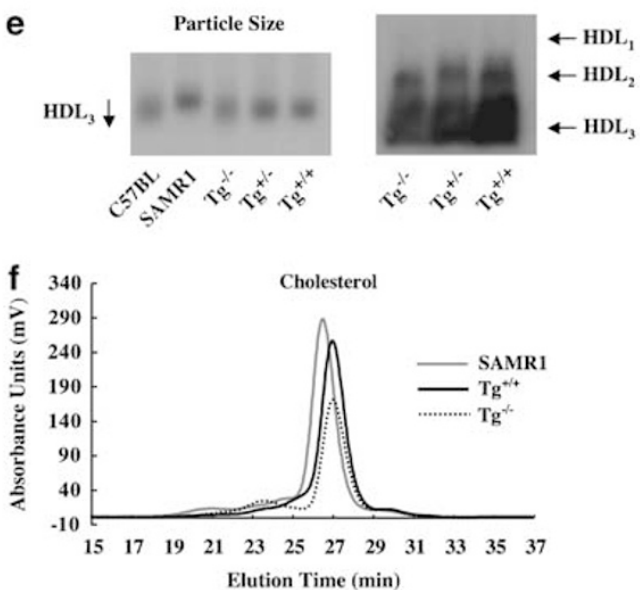

Figure 3 The plasma concentrations of apolipoproteins and cholesterols in the transgenic mice. (a) ApoA-I and apoA-II were detected with specific antisera after SDS-PAGE and western blot of $0.1 \mu \mathrm{l}$ of mouse plasma. (b) The plasma concentrations of apoA-I and apoA-II were quantitated using a densitometric image analyzer with $\mathrm{NIH}$ Images. The number of mice used were: 3, 3, 9, 13 and 9 for C57BL/6J, SAMR1, $\mathrm{Tg}^{-/-}, \mathrm{Tg}^{+/-}$and $\mathrm{Tg}^{+/+}$, respectively. (c) The plasma apoA-II/apoA-I ratio was calculated from the plasma concentrations (mg/dl) of apoA-I and apoA-II. (d) The concentrations of total and HDL cholesterol were determined by an enzymatic procedure. (e) HDL particle size was analyzed by native 5-15\% PAGE of $3 \mu$ l mouse plasma prestained for neutral lipids using Sudan Black B. SAMR1 with Apoa $2^{b}$ allele and C57BL/6J with Apoa $2^{a}$ allele were used as a control for comparison with the transgenic mice $\left(\mathrm{Tg}^{-/-}, \mathrm{Tg}^{+/-}\right.$, and $\left.\mathrm{Tg}^{+/+}\right)$. The distribution of apoA-Il protein among the $\mathrm{HDL}$ species $\left(\mathrm{HDL}_{1}, \mathrm{HDL}_{2}\right.$ and $\left.\mathrm{HDL}_{3}\right)$ was determined by western blot analysis of $0.1 \mu \mathrm{l}$ plasma separated by native PAGE. (f) Cholesterol profiles in plasma lipoproteins were analyzed by a dual detection HPLC system. Overexpression of Apoa2 ${ }^{C}$ mRNA did not change the particle size of HDL but increased concentration in $\mathrm{Tg}^{+/+}$mice. Values are means $\pm \mathrm{s}$.d. $\left({ }^{*}<<0.05,{ }^{*} P<0.01\right)$.

induced severe amyloid deposition that was observed by green birefringence under polarizing microscopy in the spleen (Figure 4a and $\mathrm{d}$ ), liver (Figure $4 \mathrm{~b}$ and e), tongue (Figure $4 \mathrm{c}$ and $\mathrm{f}$ ), testis, kidney, heart, stomach, intestine and skin after 2 months, while no amyloid deposition was observed in the brain. The amyloid deposition stained positively with anti-AApoAII antiserum (Figure $4 \mathrm{~g}-\mathrm{i}$ ) but negatively with anti-AA antiserum immunohistochemically (data not shown). To analyze amyloid deposition in tissues, we isolated amyloid fibrils from the liver of $\mathrm{Tg}^{+1+}$ mice treated with AApoAII amyloid fibrils. Western blot analysis identified the protein as AApoAII (Figure 5a). We observed negatively stained amyloid fibrils by transmission electron microscopy (Figure $5 \mathrm{~b}$ ), the fibrils were rigid, nonbranching and $\sim 10 \mathrm{~nm}$ in diameter. We compared the levels of amyloid deposition in the six major organs of spleen, heart, liver, tongue, stomach and intestine using a grading system. ${ }^{13}$ In transgenic positive mice, significantly higher amyloid depositions were observed in all organs except for the stomach as compared with $\mathrm{Tg}^{-1-}$ mice (Figure 6). No amyloid deposition was observed in the brain in any strain. To quantitate the relative sensitivities of $\mathrm{mApoa} 2^{c}$ transgenic mice to induction of amyloidosis by amyloid fibrils, the AApoAII amyloid fibrils were serially diluted in distilled water and injected into the tail vein of $\mathrm{Tg}^{-1-}, \mathrm{Tg}^{+/-}$and $\mathrm{Tg}^{+1+}$ mice at doses ranging from $10^{-8}$ to $1 \mu \mathrm{g}$. Mice were killed 2 months after the injections. The degree of amyloid deposition in the whole body was compared using the AI in the seven organs (Figure 7a). Small amyloid deposits were found in four of the eight $\mathrm{Tg}^{+1+}$ mice after injection of $10^{-8} \mu \mathrm{g}$ AApoAII fibrils; no deposition was detected in $\mathrm{Tg}^{-1-}$ and $\mathrm{Tg}^{+/-}$mice. We found amyloid deposition in $\mathrm{Tg}^{+/-}$and $\mathrm{Tg}^{+/+}$mice and no deposition in $\mathrm{Tg}^{-1-}$ mice after injection of $10^{-5} \mu \mathrm{g}$ fibrils. When $10^{-3} \mu \mathrm{g}$, $10^{-1} \mu \mathrm{g}$ and $1 \mu \mathrm{g}$ AApoAII fibrils were injected, the degree of amyloid deposition increased in a dose-dependent manner in all $\mathrm{Tg}^{-/-}, \mathrm{Tg}^{+/-}$and $\mathrm{Tg}^{+/+}$mice. However, AI values were 

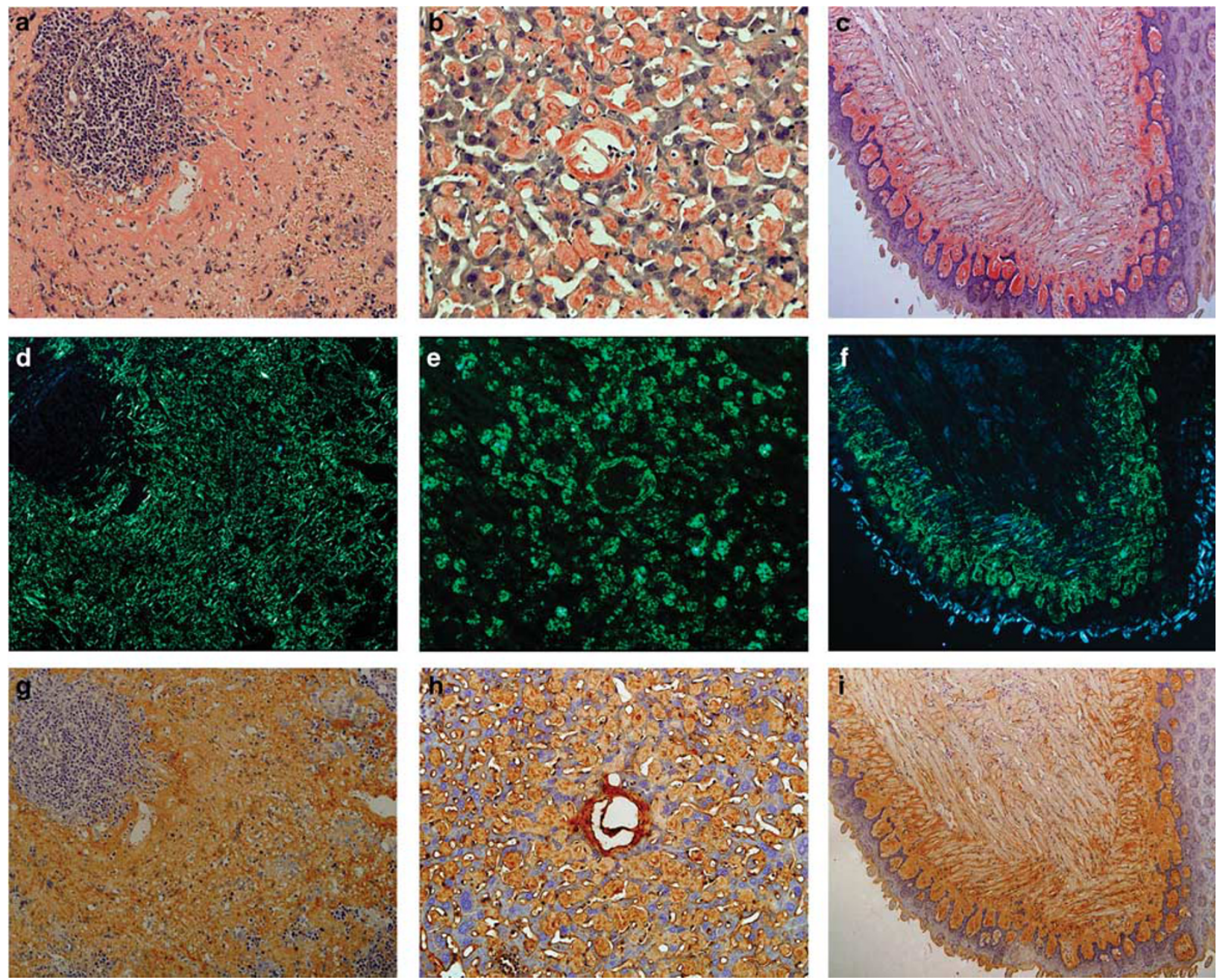

Figure 4 Heavy AApoAll amyloid deposition in tissues of transgenic mice. Amyloid deposition was observed in (a), (d), (g) spleen, (b), (e), (h) liver, and (c), (f), (i) tongue from $\mathrm{Tg}^{+/+}$mice obtained 2 months after injection of $1 \mu \mathrm{g}$ of AApoAll. (a, $\mathbf{b}$ and $\mathbf{c}$ ), amyloid deposition was identified by red color in Congo stained sections. (d, e and $\mathbf{f}$ ), heavy amyloid fibril deposition was observed by green birefringence in polarizing microscopy. (g, $\mathbf{h}$ and $\mathbf{i})$, AApoAll amyloid deposition was confirmed immunohistochemically with anti-AApoAll antiserum. Optical magnification, $\times 100(\mathbf{c}, \mathbf{f}$ and $\mathbf{i})$, and $\times 200(\mathbf{a}, \mathbf{b}, \mathbf{d}, \mathbf{e}, \mathbf{g}$, and $\mathbf{h}$ ).

significantly different between the strains and always in the following order: $\mathrm{Tg}^{-1-}<\mathrm{Tg}^{+/-}<\mathrm{Tg}^{+/+}$. Amyloid deposits were observed only in the tongue, spleen, stomach and small intestine at low quantities of injected AApoAII fibrils $\left(10^{-8} \mu \mathrm{g}\right.$ in $\mathrm{Tg}^{+/+}$and $10^{-3} \mu \mathrm{g}$ in $\mathrm{Tg}^{-/-}$mice) (Figure $\left.7 \mathrm{~b}\right)$. To characterize the rate at which deposition occurred in mApoa $2^{c}$ transgenic mice $\left(\mathrm{Tg}^{+/+}\right)$, AI was determined 1,2 and 3 months after injection of $1 \mu \mathrm{g}$ amyloid fibrils (Figure 7c). The amyloid deposition was observed in all three strains 1 month after injection. The extent of amyloid deposition (AI) further increased 2 and 3 months after injection. AI values were significantly different between strains and always in the following order: $\mathrm{Tg}^{-/-}<\mathrm{Tg}^{+/-}<\mathrm{Tg}^{+/+}$. Amyloid deposition was found systemically in the liver, heart, lungs, spleen, tongue, stomach, intestine and skin in $\mathrm{Tg}^{+/+}$mice (Figure 7d). Amyloid deposition was found only in the tongue, heart and stomach in $\mathrm{Tg}^{-1-}$ mice 1 month after injection, but found in the liver, heart, lungs, spleen, tongue, stomach, intestine and skin 3 months after injection. The distribution profiles of amyloid in the organs did not show any difference in all $\mathrm{Tg}^{-/-}, \mathrm{Tg}^{+/-}$and $\mathrm{Tg}^{+/+}$mice. Namely, some particular organs showed earlier deposition, always in this order: tongue, intestine and stomach, spleen and heart, liver.

\section{DISCUSSION}

In mice, spontaneous senile apoA-II amyloidosis is universally present. ${ }^{30}$ Severe apoA-II amyloidosis is linked to the Apoa2 $^{c}$ allele (Gln5, Ala38). Here, we report the establishment of a new apoA-II transgenic mouse strain that overexpresses the $\mathrm{mApoa} 2^{c}$ allele. Our long-term goal is to use this model to elucidate metabolic features of the amyloidogenic Apoa $2^{c}$ allele and the pathogenesis of amyloidosis. This 
a
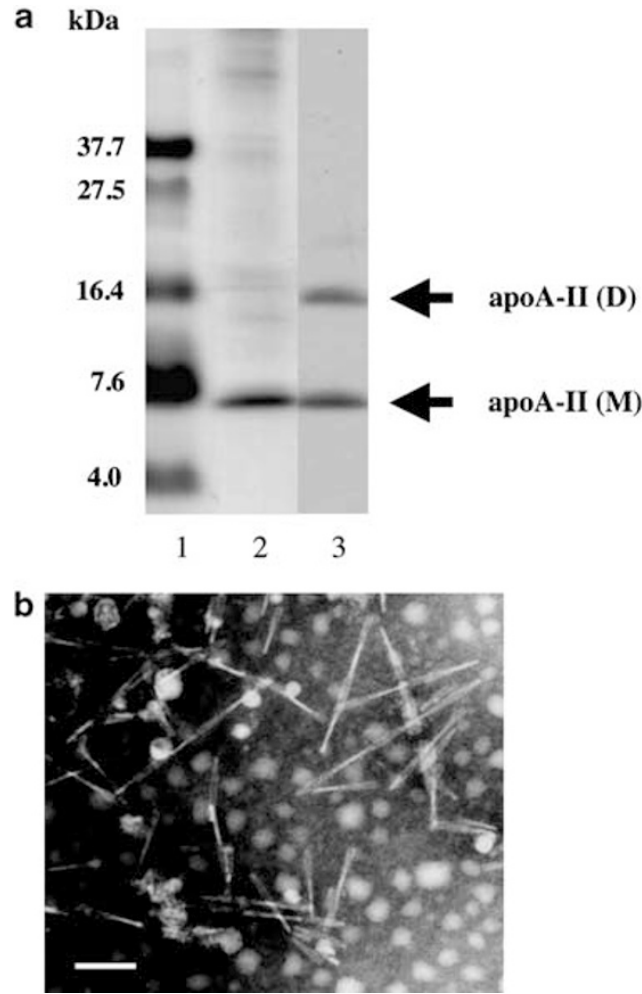

Figure 5 The identification of amyloid fibrils deposited in tissue. (a) Amyloid fibrils were extracted as water-suspended fraction from the liver of $\mathrm{Tg}^{+1+}$ mice 2 months after $1 \mu \mathrm{g}$ AApoAll injection and were separated by SDS-PAGE. The gel was stained with Coomassie Brilliant Blue R-250. Molecular weight marker (lane 1), amyloid fibrils of the liver (lane 2). Western blot analysis of amyloid fibrils, detected with anti-AApoAll antiserum, two bands showed monomer and dimer (lane 3). (b) Transmission electron microscopic images showed the negatively stained amyloid fibrils isolated as a water-suspended fraction of the liver of $\mathrm{Tg}^{+/+}$ mice 2 months after AApoAll injection. Amyloid fibrils were rigid, nonbranching, $\sim 10 \mathrm{~nm}$ in diameter and $439 \mathrm{~nm}$ in mean length. The scale bar indicates $200 \mathrm{~nm}$.

strain has much improved sensitivity to induction of amyloidosis by amyloid fibrils.

We have previously showed that the degree of senile apoAII amyloid deposition in mouse strains varied with the apoAII allele such that $A$ poa $2^{c}>A$ poa $2^{a}>A$ Apoa $2^{b}{ }^{13,14}$ Elucidation of the mechanism by which amyloidogenic apoA-IIs (Apoa2 $2^{c}$ and $A p o a 2^{a}$ ) induce a low concentration of HDL should shed light on the pathogenesis of amyloidosis (Figure 3). We have previously demonstrated that the mRNA level, synthesis rate, plasma clearance rates and translational efficiencies of apoAII were similar in SAMP1 $\left(\right.$ Apoa $\left.^{c}\right)$ and SAMR1 $\left(\right.$ Apoa $\left.^{b}\right)$ mice. Impaired secretion was suggested in $A p o a 2^{c}$ mice. $^{31,32}$ Amyloidogenic apoA-IIs may be retained in the endoplasmic reticulum (ER) by the ER quality control system. ${ }^{33,34}$ Overexpression of apoA-II under the CAGGS enhancer/promoter increased plasma apoA-II from $39 \mathrm{mg} / \mathrm{dl}\left(\mathrm{Tg}^{-/-}\right)$to $61 \mathrm{mg} / \mathrm{dl}$ $\left(\mathrm{Tg}^{+/+}\right)$resulting in apoA-II concentration 1.57 times higher than in $\mathrm{Tg}^{-1-}$ mice. Increased apoA-II was associated

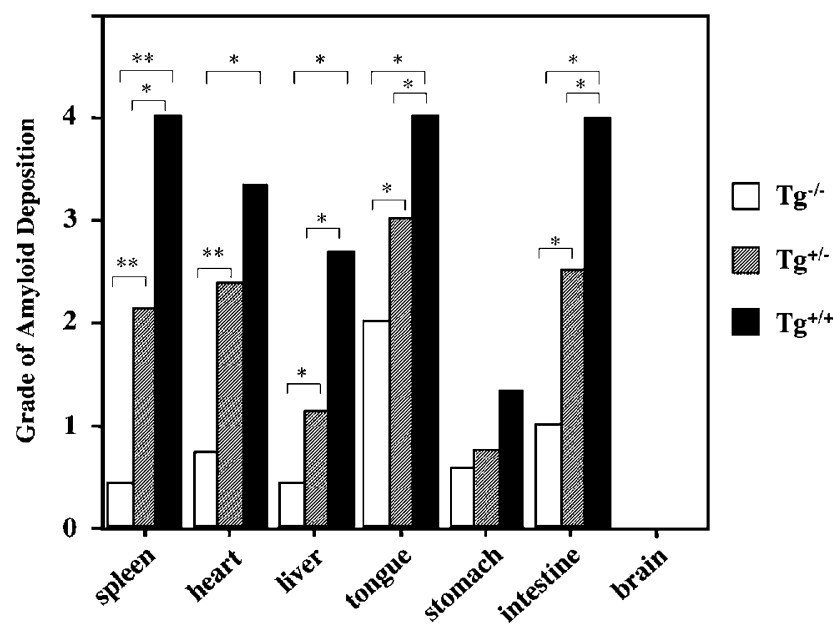

Figure 6 Comparison of amyloid deposition in major organs of AApoAlltreated mice. The grade of amyloid deposition in the spleen, heart, liver, tongue, stomach, intestine and brain was determined using Congo redstained sections. ${ }^{13}$ The degrees of deposition were significantly different among the $\mathrm{Tg}^{-1-}, \mathrm{Tg}^{+/-}$and $\mathrm{Tg}^{+/+}$mice in all organs except for the stomach $\left({ }^{*} P<0.05 ;{ }^{*} P<0.01\right.$, Mann-Whitney $U$-test). No amyloid deposition was observed in the brain.

with an increased concentration of HDL and total cholesterol. These results were consistent with those observed in C57BL/6J transgenic mice that overexpressed the Apoa $2^{a}$ gene ${ }^{35,36}$ and R1.P1-Apoa2 ${ }^{c}$ mice that overexpressed the Apoa ${ }^{b}$ gene. $^{37}$ Highly expressed apoA-II associated with all species of HDL but mainly with $\mathrm{HDL}_{3}$ particles. The particle size of HDL did not change in $\mathrm{mApoa} 2^{c}$ transgenic mice, different from mice overexpressing Apoa $2^{b}$ and Apoa2 ${ }^{a}$.

More severe amyloid deposition was observed in the body of $\mathrm{Tg}^{+/+}$mice compared to $\mathrm{Tg}^{-1-}$ mice. Thus, the plasma concentration of amyloid protein contributes to the progress of systemic apoA-II amyloidosis. In our previous study, we reported that SAMP1 mice that were fed a fish oil diet had significantly lower apoA-II concentrations but more AApoAII deposits than those on a butter and safflower oil diet. ${ }^{38}$ These results suggested altered metabolism or clearance of amyloid protein might be another factor controlling susceptibility towards amyloidosis. ${ }^{39}$ ApoA-II is synthesized mainly in the liver in mice and secreted to the blood very quickly. Thus, the amount of apoA-II protein in the liver represented by western blot was very low in $\mathrm{Tg}^{-/-}$mice. On the other hand, apoA-II proteins detected in the heart and tongue might be in the blood, whereby perfusion did not wash them away completely. But in $\mathrm{Tg}^{+/+}$mice, apoA-II mRNA and proteins were expressed in almost all tissues examined. We have previously suggested a possible contribution of apoA-II synthesized in extrahepatic tissues to local amyloid deposition. ${ }^{40}$ We expected that such extrahepatic synthesis might influence tissue distribution of amyloid deposition after fibril injection. However, notable differences were not observed in tissue distribution of amyloid deposi- 

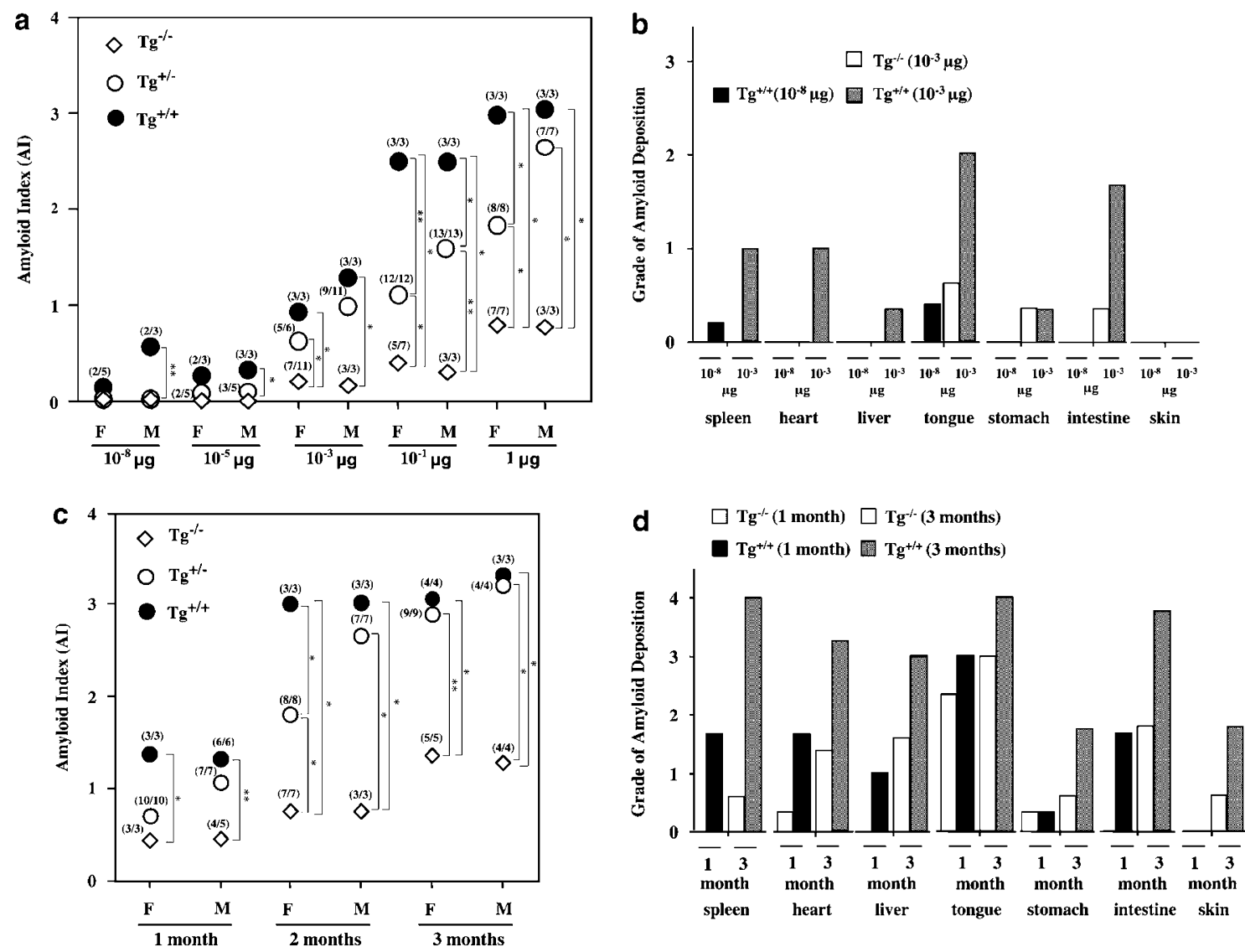

Figure 7 Enhanced sensitivity to the induction of amyloidosis by amyloid fibrils in transgenic mice. Amyloid deposition was induced by the injection of AApoAll fibrils. (a) The intensity of AApoAll amyloid deposition was determined semi-quantitatively using the Al parameter, 2 months after female and male $\mathrm{Tg}^{-/-}(\diamond), \mathrm{Tg}^{+/-}(\bigcirc)$ and $\mathrm{Tg}^{+/+}(\bullet)$ mice received intravenous injections of $10^{-8}, 10^{-5}, 10^{-3}, 10^{-1}$ and $1 \mu \mathrm{g}$ AApoAll amyloid fibrils. The Al parameter represents the average degree of AApoAll deposition in the major seven organs ${ }^{13}$ (b) Comparison of amyloid deposition in each major organ of $10^{-8}$ and $10^{-3}$ AApoAll treated $\mathrm{Tg}^{-/-}$and $\mathrm{Tg}^{+/+}$mice. The first amyloid deposition was observed in the tongue both in $\mathrm{Tg}^{-1-}$ and $\mathrm{Tg}^{+/+}$mice. (c) The intensity of AApoAll amyloid deposition (Al) was determined in female and male $\mathrm{Tg}^{-1-}, \mathrm{Tg}^{+/-}$and $\mathrm{Tg}^{+/+}$mice 1,2 and 3 months after intravenous injections of $1 \mu \mathrm{g}$ AApoAll amyloid fibrils. (d) Amyloid deposition in each major organ was compared among $\mathrm{Tg}^{-1-}$ and $\mathrm{Tg}^{+/+}$mice 1 and 3 months after intravenous injections of $1 \mu \mathrm{g}$ AApoAll amyloid fibrils. Figures in parentheses represent numbers of amyloid positive mice/numbers of mice examined. ${ }^{*} P<0.05$; ${ }^{*} P<0.01$, Mann-Whitney U-test.

tion between $\mathrm{Tg}^{+1+}$ and $\mathrm{Tg}^{-1-}$ mice, even though deposition was heavier and earlier in $\mathrm{Tg}^{+/+}$mice. These results suggest that amyloid protein in blood may be the sole major source of amyloid fibrils in each tissue. In particular, we did not find any amyloid deposits in the brain in spite of the expression of apoA-II mRNA and protein in $\mathrm{Tg}^{+/+}$mice. We offer three possible explanations: (1) the level of apoA-II protein in the brain was too low to form deposits, (2) the blood-brain barrier prevented the AApoAII fibrils from invading the brain, and (3) other environmental factors such as inflammation were necessary for deposition in the brain. ${ }^{39}$

We determined the apoA-II transgene insertion site. Homozygous $\mathrm{Tg}^{+1+}$ mice had four extra copies of the Apoa $2^{c}$ gene. The insertion of vector DNA into the centromeric region of chromosome 13 eliminated $4784 \mathrm{bp}$ of genomic DNA accompanied with insertion of transposon elements, IAP and LINE. No genes could be identified in the lost DNA, and the neighboring genes may be too far away to be affected by the CAGGS enhancer/promoter insertion elements. Thus, overexpression of apoA-II under the CAGGS enhancer/promoter is likely to be the cause for the severe amyloid deposition in $\mathrm{Tg}^{+/+}$mice.

Prion diseases are characterized by abnormal deposits of amyloid fibrils as amyloid plaques which induce neurologic damage. ${ }^{41,42}$ Such fibrils, which are self-propagating protein conformations occurring both in vitro and in vivo, ${ }^{43-50}$ are thus transmissible. When small nuclei or fibril seeds are present, they dramatically accelerate fibril formation by inducing conformational changes in amyloid protein monomers. Thus, in non-prion amyloidosis, the conformational change induced by preexisting amyloid fibrils might make the disease transmissible. ${ }^{3,51-53}$ Here, we induced apoA-II amyloidosis by injection of AApoAII amyloid fibrils in $\mathrm{mApoa2}$ transgenic mice. Without induction, $\mathrm{Tg}^{+/+}$and $\mathrm{Tg}^{+/-}$mice 
did not show spontaneous amyloid deposition until 6 months of age (data not shown). $\mathrm{Tg}^{+/+}$and $\mathrm{Tg}^{+/-}$mice had increased sensitivity to amyloid fibril injection. Amyloid deposition could be detected in $\mathrm{Tg}^{+/+}$mice injected with $10 \mathrm{fg}$ of amyloid fibrils. On the other hand, amyloid deposition was detected only in $\mathrm{Tg}^{-1-}$ mice injected more than $1 \mathrm{ng}$ of amyloid fibrils (Figure 7a). Amyloid deposition was detected in many organs in $\mathrm{Tg}^{+/+}$mice 1 month after injection of amyloid fibrils (Figure $7 \mathrm{~d}$ ). Thus the period for detection decreased to less than 1 month compared to $\mathrm{Tg}^{-1-}$ mice. $^{54}$

Since fibrilization of several kinds of amyloid proteins is nucleation-dependent, self- and cross-seeding by amyloid fibrils and amyloid fibril-like materials is thought to be a key factor for the progress of amyloidosis. To elucidate the pathogenesis of amyloidosis and to prevent it, it is necessary to improve the current bio-assay system for detection of amyloid fibrils and amyloidogenic materials in the environment. Ideally, the system should have a higher sensitivity and shorter waiting period than in R1.P1-Apoa2 $2^{c}\left(\mathrm{Tg}^{-/-}\right)$mice. The mechanism by which the injected apoA-II fibrils gain access to the tissue remains to be elucidated. We found that the content of apoA-II in HDL particles did not change after incubation of HDL with sonicated AApoAII amyloid fibrils (data not shown). This suggests that typical or fragmented amyloid fibrils do not associate with HDL particles. We believe amyloid fibrils are too large to associate with HDL particles. In mouse apoA-II amyloidosis following induction by amyloid fibrils, the amyloid first deposits in the tongue, stomach and intestine, then extends to other tissues. A difference in access of the fibrils to different tissues may account for the distribution of the induced amyloidosis. We could not exclude the possibility that HDL and other lipoprotein particles might bind to injected fibrils and contribute to the access of fibrils to certain tissues. The new Apoa2 $2^{c}$ transgenic mouse strain with high sensitivity to exogenous amyloid fibrils should be helpful to elucidate such issues.

Several conditions might contribute to the progress of amyloidosis: (1) structures or mutations of amyloid proteins, ${ }^{18}(2)$ levels of the amyloid proteins in the blood or local environment in each tissue, (3) transmission of amyloidogenic materials and (4) other environmental conditions such as inflammation, nutrition and aging. In particular, many tissue factors that facilitate the metabolism, aggregation or stability of amyloid fibrils may contribute to a differential tissue distribution of amyloid deposition. Such factors might include the quality control system of proteins in ER, molecular chaperones preventing protein aggregation, proteoglycans increasing fibril stability in the extracellular space and fibril degradation by proteases. Here, we have established a new transgenic mouse strain of an amyloidogenic apoA-II variant (APOA2C), which showed significantly increased sensitivity to induction of amyloidosis associated with an increased concentration of APOA2C. Mouse apoA-II amyloidosis shares many properties with other types of amyloi- dosis. This line should be a valuable tool to investigate amyloidosis-associated conditions and factors, and should provide important insights into diseases of protein misfolding.

\section{ACKNOWLEDGEMENTS}

We thank Ayako Nishida and Kiyoshi Matsumoto (Research Center for Human and Environmental Science, Shinshu University) for taking care of mice and Kiyokazu Kametani for assistance with the histological studies. This work was supported by Grants-in-Aid for Priority Areas (17028018) and Scientific Research (B) (17390111) from the Ministry of Education, Culture, Sports, Science, and Technology of Japan and by a grant from the Intractable Disease Division, the Ministry of Health, Labor and Welfare, Research Committees for Amyloidosis in Japan and for Epochal Diagnosis and Treatment of Amyloidosis in Japan.

1. Selkoe DJ. Folding proteins in fatal ways. Nature 2003;426:900-904.

2. Glenner GG. Amyloid deposits and amyloidosis: the beta-fibrilloses. N Engl J Med 1980;302:1283-1292.

3. Merlini G, Bellotti V. Molecular mechanisms of amyloidosis. N Engl J Med 2003;349:583-596.

4. Higuchi K, Yonezu T, Kogishi K, et al. Purification and characterization of a senile amyloid-related antigenic substance (apoSAS ${ }_{S A M}$ ) from mouse serum. apoSAS $S_{S A M}$ is an apoA-II apolipoprotein of mouse high density lipoproteins. J Biol Chem 1986;261:12834-12840.

5. Higuchi K, Matsumura A, Honma A, et al. Systemic senile amyloid in senescence-accelerated mice: a unique fibril protein demonstrated in tissues from various organs by the unlabeled immunoperoxidase method. Lab Invest 1983;48:231-240.

6. Higuchi K, Kitagawa K, Naiki H, et al. Polymorphism of apolipoprotein A-II (apoA-II) among inbred strains of mice. Relationship between the molecular type of apoA-II and mouse senile amyloidosis. Biochem J 1991;279:427-433.

7. Kitagawa K, Wang J, Matsushita T, et al. Polymorphism of mouse apolipoprotein A-II: seven alleles found among 41 inbred strains of mice. Amyloid 2003;10:207-214.

8. Higuchi $\mathrm{K}$, Naiki H, Kitagawa $\mathrm{K}$, et al. Apolipoprotein A-ll gene and development of amyloidosis and senescence in a congenic strain of mice carrying amyloidogenic ApoA-II. Lab Invest 1995;72:75-82.

9. Higuchi K, Wang J, Kitagawa K, et al. Accelerated senile amyloidosis induced by amyloidogenic apoA-II genes shortens the life span of mice but does not accelerate the rate of senescence. J Gerontol Biol Sci 1996;51:295-302.

10. Wang J, Matsushita T, Kogishi K, et al. Wild type ApoA-Il gene does not rescue senescence-accelerated mouse (SAMP1) from short life span and accelerated mortality. J Gerontol Biol Sci 2000;55:432-439.

11. Higuchi K, Kogishi K, Wang J, et al. Fibrilization in mouse senile amyloidosis in fibril conformation-dependent. Lab Invest 1998;78:1535-1542.

12. Xing $Y$, Nakamura A, Chiba $T$, et al. Transmission of mouse senile amyloidosis. Lab Invest 2001;81:493-499.

13. Xing $Y$, Nakamura $A$, Korenaga $T$, et al. Induction of protein conformational change in mouse senile amyloidosis. J Biol Chem 2002;277:33164-33169.

14. Korenaga $T$, Fu X, Xing $Y$, et al. Tissue distribution, biochemical properties, and transmission of mouse type A AApoAll amyloid fibrils. Am J Pathol 2004;164:1597-1606.

15. Fu X, Korenaga T, Fu L, et al. Induction of AApoAll amyloidosis by various heterogeneous amyloid fibrils. FEBS Letters 2004;563:179-184.

16. Lundmark K, Westermark G, Nystrom S, et al. Transmissibility of systemic amyloidosis by a prion-like mechanism. Proc Natl Acad Sci USA 2002;99:6979-6984.

17. Cui $D$, Kawano $H$, Takahashi $M$, et al. Acceleration of murine AA amyloidosis by oral administration of amyloid fibrils extracted from different species. Pathol Int 2002;52:40-45.

18. Xing Y, Higuchi K. Amyloid fibril proteins. Mech Ageing Dev 2002;123:1625-1636.

19. Yagi $H$, Kusaka $E$, Hongo $K$, et al. Amyloid fibril formation of alphasynuclein is accelerated by preformed amyloid seeds of other proteins: implications for the mechanism of transmissible conformational diseases. J Biol Chem 2005;280:38609-38616. 
20. $O^{\prime}$ Nuallain $B$, Williams $A D$, Westermark $P$, et al. Seeding specificity in amyloid growth induced by heterologous fibril. J Biol Chem 2004:279:17490-17499.

21. Tanaka M, Chien P, Yonekura K, et al. Mechanism of cross-species prion transmission: an infectious conformation compatible with two highly divergent yeast prion proteins. Cell 2005;121:49-62.

22. Niwa H, Yamamura K, Miyazaki J. Efficient selection for high-expression transfectants with a novel eukaryotic vector. Gene 1991;108:193-199.

23. Saborio GP, Permanne B, Soto C. Sensitive detection of pathological prion protein by cyclic amplification of protein misfolding. Nature 2001;411:810-813.

24. Schagger $\mathrm{H}$, Jagow GV. Tricine-sodium dodecyl sulfate-polyacrylamide gel electrophoresis for the separation of proteins in the range from 1 to $100 \mathrm{kDa}$. Anal Biochem 1987;166:368-379.

25. Chiba T, Kogishi K, Wang J, et al. Mouse senile amyloid deposition in suppressed by adenovirus-mediated over-expression of amyloid resistant apolipoprotein A-II. Am J Pathol 1999;155:1319-1326.

26. Higuchi K, Kitado H, Kitagawa K, et al. Development of congenic strains of mice carrying amyloidogenic apolipoprotein A-II $\left(A p o a 2^{C}\right)$ reduces the plasma level and the size of high density lipoprotein. FEBS Lett 1993;317:207-210.

27. Usui S, Hara Y, Hosaki S, et al. A new on-line dual enzymatic method for simultaneous quantification of cholesterol and triglycerides in lipoproteins by HPLC. J Lipid Res 2001;43:805-814.

28. Pras M, Zucker-Franklin D, Rimon A, et al. Physical, chemical, and ultrastructural studies of water-soluble human amyloid fibril. J Exp Med 1969;130:777-791.

29. Puchtler $\mathrm{H}$, Sweet $\mathrm{F}$, Levine $M$. On the binding of Congo red by amyloid. J Histochem Cytochem 1962;10:355-364.

30. Higuchi K, Naiki H, Kitagawa K, et al. Mouse senile amyloidosis: ASSAM amyloidosis in mice presents universally as a systemic age-associated amyloidosis. Virchows Arch B Cell Pathol 1991;60:231-239.

31. Wang J, Kitagawa K, Kitado $\mathrm{H}$, et al. Regulation of the metabolism of plasma lipoproteins by apolipoprotein A-II. Biochim Biophys Acta 1997:1345:248-258.

32. Kitagawa K, Naiki H, Takeda T, et al. Age-associated decreases in the messenger ribonucleic acid level and the rate of synthesis of apolipoprotein A-II in murine senile amyloidosis. Lab Invest 1994;70:565-571.

33. Cohen FE, Kelly J. Therapeutic approaches to protein-misfolding diseases. Nature 2003;426:905-909.

34. Sekijima Y, Wiseman RL, Matteson J, et al. The biological and chemical basis for tissue-selective amyloid disease. Cell 2005;121:73-85.

35. Warden C, Hedrick C, Qiao J, et al. Atherosclerosis in transgenic mice overexpressing apolipoprotein A-II. Science 1993;261:469-472.

36. Hedrick C, Castellani L, Warden C, et al. Influence of mouse apolipoprotein A-II on plasma lipoproteins in transgenic mice. J Biol Chem 1993;268:20676-20682.
37. Chiba T, Kogishi K, Wang J, et al. Mouse senile amyloid deposition is suppressed by adenovirus-mediated over-expression of amyloid resistant apolipoprotein A-II. Am J Pathol 1999;155: 1319-1326.

38. Umezawa M, Tatematsu K, Koregana $\mathrm{T}$, et al. Dietary fat modulation of apoA-II metabolism and prevention of senile amyloidosis in the senescence-accelerated mouse. J Lipid Res 2003:44:762-769.

39. Guo Z, Mori M, Fu X, et al. Amyloidosis modifier genes in the less amyloidogenic A/J mouse strain. Lab Invest 2003;83:1605-1613.

40. Li F, Ikuo M, Takuya C, et al. Extrahepatic expression of apolipoprotein A-II in mouse tissues: possible contribution to mouse senile amyloidosis. J Histochem Cytochem 2001;49:739-747.

41. Bendheim P, Barry R, DeArmond $S$, et al. Antibodies to a scrapie prion protein. Nature 1984:310:418-421.

42. DeArmond S, McKinley M, Barry R, et al. Identification of prion amyloid filaments in scrapie-infected brain. Cell 1985:41:221-235.

43. Chesebro B, Trifilo M, Race R, et al. Anchorless prion protein results in infectious amyloid disease without clinical scrapie. Science 2005;308:1435-1439.

44. Silveira J, Raymond G, Hughson A, et al. The most infectious prion particle. Nature 2005;437:257-261.

45. Kicisko D, Come J, Priola S, et al. Cell-free formation of proteaseresistant prion protein. Nature 1994;370:471-474.

46. Butler D, Scott MRD, Bockman J, et al. Scrapie-infected murine neuroblastoma cells produce protease-resistant prion proteins. J Virol 1988;62:1558-1564.

47. Caughey B, Race R, Ernst D, et al. Prion protein-biosynthesis in scrapieinfected and uninfected neuroblastoma cells. J Virol 1989;63:175-181.

48. Patino M, Liu J, Glover J, et al. Support for the prion hypothesis for inheritance of a phenotypic trait in yeast. Science 1996;273:622-626.

49. Paushkin S, Kushnirov V, Smirnov V, et al. Propagation of the yeast prion-like [psi+] determinant is mediated by oligomerization of the SUP35-encoded polypeptide chain release factor. EMBO J 1996;15:3127-3134.

50. Telling G, Scott M, Mastrianni J, et al. Prion propagation in mice expressing human and chimeric PrP transgenes implicates the interaction of cellular PrP with another protein. Cell 1995;83:79-90.

51. Booth $D$, Sunde $M$, Bellotti $B$, et al. Instability, unfolding and aggregation of human lysozyme variants underlying amyloid fibrillogenesis. Nature 1997;385:787-793.

52. Kelly J. Alternative conformations of amyloidogenic proteins govern their behavior. Curr Opin Struct Biol 1996;6:11-17.

53. Lai Z, Colon W, Kelly J. The acid-mediated denaturation pathway of transthyretin yields a conformational intermediate that can selfassemble into amyloid. Biochemistry 1996;35:6470-6482.

54. Zhang H, Sawashita J, Higuchi K. Transmissibility of mouse AApoAll amyloid fibrils: inactivation by physical and chemical methods. FASEB $J$ 2006:20:1012-1014. 